\title{
O ensino e práticas de cuidado: o caso de um curso de graduação em enfermagem*
}

\author{
Rita da Cruz Amorim 1 \\ Eleonora Meniccuci de Oliveira²
}

\begin{abstract}
Amorim RC, Oliveira EM. O ensino e práticas de cuidado: o caso de um curso de graduação
\end{abstract} em enfermagem. Acta Paul Enferm 2005; 18(1):25-30.

\begin{abstract}
RESUMO: Vivências e inquietações construídas ao longo da formação e atuação profissional da autora motivaram esta pesquisa, tendo como objeto o processo de ensino do cuidar/cuidado em um Curso de Enfermagem que teve por objetivo analisar o processo de formação da enfermeira, buscando conhecer sua dinâmica sob a ótica de docentes da Área de Saúde do Adulto, discentes e egressas do curso. Com base no conhecido, por meio do material empírico, os significados do ensinar e aprender o cuidar/cuidado foram descritos e analisados, fazendo uma reflexão a respeito da formação dessas profissionais. A abordagem metodológica foi a qualitativa com o método de Estudo de Caso. A coleta de material foi realizada por meio da técnica de entrevista com roteiro semi-estruturado. Para análise do material, foi trabalhada a estratégia metodológica do Discurso do Sujeito Coletivo. As análises dos discursos possibilitaram a criação de temáticas, sendo abordada neste artigo a que trata do cuidar/cuidado, como objeto de trabalho da Enfermagem e sua construção para uma prática social.
\end{abstract}

Descritores: Ensino; Educação em enfermagem; Cuidados de enfermagem

- Artigo recebido em 26/03/04 e aprovado em 17/07/04

\section{INTRODUÇÃO}

Esta investigação vem ao encontro das vivências e inquietações construídas ao longo de minha formação na qualidade de estudante $\mathrm{e}$ da atuação profissional ora como enfermeira, ora como educadora.

No Curso de Enfermagem, era graduanda e podia perceber a importância atribuída ao aprendizado dos conteúdos e procedimentos técnicos, muitas vezes, chegando esse proces- so de ensino a ser torturante com provas técnicas em laboratório e nas práticas nas unidades de assistência à saúde quando desenvolvíamos as atividades com os clientes, predominavam as avaliações que privilegiavam os erros.

Em minha atuação com o cliente, muitas vezes, só pensava em realizar o procedimento técnico, se estava correto, ficando atenta, na maioria das vezes, às várias patologias que faziam parte do ambien- te hospitalar que, em um dado momento, o cliente vivenciava. Acredito que existia uma intenção de cuidado, porém, centrada no físico, na técnica.

No campo de prática, a tensão, o medo de não acertar, por um lado, para não comprometer a vida do cliente, por outro, a questão da nota que nos aprovaria ou não nas disciplinas, eram outro fator complicador do processo de ensino e aprendizagem na época.

\footnotetext{
* Parte da tese de mestrado em Enfermagem apresentada ao Programa de Pós - Graduação da Universidade Federal de São Paulo (UNIFESP) 2003. Área de concentração Saúde do Adulto. E-mail: ritaamorim2003@uol.com.br

1 Enfermeira. Mestranda em Enfermagem. Especialista em Metodologia da Assistência em Enfermagem, exercendo suas ativida des como enfermeira do Hospital Geral Clériston Andrade e professora auxiliar da Universidade Estadual de Feira de Santana.

2 Professora Doutora Livre docente em Saúde Coletiva do Departamento de Medicina Preventiva da UNIFESP. Orientadora.
} 
Assim, questionava-me que cuidado era esse que estava sendo ensinado e aprendido, pois a prática, denunciava um descuidado ${ }^{a}$ na relação estudante, professora e cliente. A meu ver, esse processo fragmentado, constitui-se em uma problemática na formação de enfermeira.

Esta prática tem permeado meu cotidiano de enfermeira e educadora, no que tange à forma em que se verifica o ensino do cuidar/cuidado ${ }^{\mathrm{b}}$ falado e construído com as alunas, pois o corpo docente acredita ou, pelo menos, discursa sobre a importância do ensinar as alunas a cuidar, que a profissional enfermeira ${ }^{c}$ necessita ver o ser humano em sua integralidade, mas, participando da dinâmica desse Curso não parece ter sido isso, que tem atravessado nosso saber e fazer.

O cuidado tem uma perspectiva relacional que opera com a dialética do processo de saúde e doença, incorporando a subjetividade, a afetividade, a palavra, os gestos corporais, o ato de tocar e a percepção para além da técnica ${ }^{(1)}$.

A subjetividade como categoria de análise, possibilita reconceitualizar as relações sociais codificadas e hierarquizadas, sobretudo, no mundo do trabalho. Isto tem provocado mudanças significativas no marco teórico do cuidado, com implicações concretas na prática profissional das enfermeiras ${ }^{(1)}$.

\footnotetext{
a Descuidado é entendido, neste estudo, como o que é negligenciado, não recebeu atenção, ou seja, é uma oposição ao cuidado (9-13).

b Cuidar: neste estudo, significa comportamentos e ações que envolvem conhecimentos, valores, habilidades e atitudes empreendidas no sentido de favorecer as potencialidades das pessoas para manter ou melhorar a condição humana no processo de viver ou morrer ${ }^{(14)}$.Cuidado: neste estudo, é entendido como o fenômeno resultante do processo do cuidar (14).

${ }^{c}$ Enfermeira: utilizaremos a palavra no feminino por entender que o maior contingente dessa profissão é constituído por mulher.
}

Neste, estudo problematizamos como objeto de pesquisa o processo de ensino do cuidar/cuidado no Curso de Graduação em Enfermagem, por entender o cuidado, como função primária no trabalho desenvolvido por esta profissional.

O processo de ensino do cuidar/ cuidado no Curso em estudo vivencia um momento de transição entre um modelo de ensino tradicional tecnicista, direcionado à definição e cumprimento dos conteúdos programáticos e ao desenvolvimento de habilidades relacionadas a procedimentos técnicos voltados à cura, o que tem contribuído para uma visão dicotomizada do ser humano.

Para responder a esta questão, definimos como objetivo analisar o processo de ensino do cuidar/cuidado na formação da enfermeira do Curso de Graduação em Enfermagem. Para isto, buscamos conhecer o processo de ensino do cuidar/cuidado no Curso de Graduação em estudo sob a ótica de docentes da Área de Saúde do Adulto, discentes e egressas.

A escolha das docentes da Área de Saúde do Adulto deu-se por integrar a mesma, portanto, vivenciamos os dilemas enfrentados no que tange ao ensinar e aprender o cuidar/ cuidado. Com relação às egressas, foram escolhidas aquelas que estavam inseridas no contexto hospitalar, atuando como enfermeiras, porque as disciplinas da área em estudo possuem um total de 480 horas de carga horária, sendo 320 horas desenvolvidas na rede hospitalar.

Quanto às dicentes do Curso, o critério foi estar cursando todas as disciplinas que finalizavam o curso, por entender que estas acompanharam e participaram do movimento do Curso em sua integralidade na qualidade de estudante do último período.

Pautadas no material empírico, descrevemos e analisamos os significados e valores do ensinar e aprender o cuidar/cuidado às pessoas envolvidas no estudo, fazendo uma reflexão sobre esse ensino no processo de formação das enfermeiras.

\section{CONTEXTUALIZANDO A PESQUISA QUALITATIVA \\ E CONSTRUINDO O \\ CAMINHO METODOLÓGICO}

Optamos pela pesquisa qualitativa por esta possibilitar o desvelamento de significados e valores que permeiam o processo de ensino do cuidar/cuidado no Curso de Graduação em Enfermagem.

A escolha do Estudo de Caso deu-se em razão de possibilitar uma análise aprofundada do ensino do cuidar/cuidado na Área de Saúde do Adulto do curso, o que vem ao encontro da concepção do Estudo de Caso

... como sendo uma categoria de pesquisa, cujo objeto é uma unidade que se analisa aprofundadamente... ${ }^{(2)}$.

\section{A ESCOLHA DOS SUJEITOS, TÉCNICA E DOCUMENTOS DO ESTUDO}

Participaram do estudo docentes da Área de Saúde do Adulto, alunas e egressas do Curso de Enfermagem da Universidade Estadual de Feira de Santana (UEFS). Para realizar a pesquisa, trabalhamos com um total de 33 sujeitos, sendo 12 alunas, 13 enfermeiras e oito docentes.

Estas escolhas vão ao encontro do mencionado com relação à pesquisa mais intensa em uma unidade menor, a fim de que os processos sociais possam ser analisados. Nesta perspectiva,

[...] o autor informa que o isolamento para propósitos analíticos não deveria ser confundido com isolamento de fato[... $]^{(3)}$.

Preocupadas com a qualidade do relacionamento com as participantes do estudo e o respeito a seus 
direitos de cidadãs e, também, em atenção ao Código de Ética de Enfermagem em seu artigo 35 Capítulo IV dos deveres, a Comissão de Ética em Pesquisa da Universidade Federal de São Paulo/ Escola Paulista de Medicina (UNIFESP/ EPM) que atende à Resolução 196/ 96 do Conselho Nacional de Saúde (CNS) que

... visa a assegurar os direitos e deveres que dizem respeito à comunidade científica, aos sujeitos que participaram da pesquisa e ao estado ... ,

solicitamos consentimento por escrito aos sujeitos para participarem da pesquisa, mediante apresentação de informação completa dos objetivos, riscos e benefícios, da garantia do anonimato e sigilo, do respeito à privacidade e intimidade e à sua liberdade de participar ou declinar no momento que desejasse ${ }^{(4-5)}$.

Na coleta de material, trabalhamos com a técnica de entrevista que,

... mencionam a importância das pessoas compreenderem o que ocorre umas com as outras, [...] a melhor situação para participar na mente de outro ser humano é a interação face a face, pois o caráter, inquestionável de proximidade entre as pessoas, que proporciona as melhores possibilidades de penetrar na mente, vida e definição dos indivíduos [...] ${ }^{(6)}$.

O roteiro foi semi-estruturado, o que proporcionou o estabelecimento de uma comunicação mais livre com a entrevistada. Com a intenção de aprofundar a indagação sobre o objeto do estudo, buscamos elaborar itens comuns às três categorias de sujeitos envolvidos no estudo, considerando que estes têm em comum a origem na mesma Instituição de Ensino ora como aluna, ora como ex-aluna e ora como professoras, havendo necessidade de con- templar questões específicas, já que são categorias diferentes apesar dos pontos semelhantes.

A coleta de material ocorreu nos meses de janeiro e fevereiro de 2002 e, após a leitura flutuante das entrevistas, resolvemos voltar a campo em julho de 2002 para entrevistar mais algumas docentes e enfermeiras para completar o material.

\section{AESTRATÉGIA METODOLÓGICA DO DISCURSO DO SUJEITO COLETIVO}

Para analisar o material produzido nas entrevistas, optamos pela estratégia metodológica que apresenta quatro figuras metodológicas, quais sejam: Ancoragem (A), Idéia Central (IC), Expressões-Chave (ECH), e Discurso do Sujeito Coletivo (DSC). Neste trabalho, utilizamos IC, ECH, e o DSC ${ }^{(7)}$.

\section{ANALISANDO OS DISCURSOS DO SUJEITO COLETIVO}

A análise foi realizada com base na articulação dos DSCs construídos pelas Idéias Centrais. Aqui discutiremos a temática que tratou do cuidar/cuidado, como objeto de trabalho da Enfermagem e sua construção para uma prática social.

[..].Cuidar, prestar cuidado, tomar conta é primeiro que tudo, um acto de VIDA, no sentido de que representa uma variedade infinita de actividades que visam manter, sustentar a VIDA e permitir-lhe continuar e reproduzir-se $[\ldots]^{(8)}$.

As enfermeiras são as profissionais que têm uma relação direta com o cuidar/cuidado humano, pois no exercício de suas atividades acompanham os utilizadores do cuidado de maneira imediata e constante, seja promovendo o cuidado direto ou criando condições para execução das ações de cuidado.
O cuidar é uma atitude que envolve ocupação, preocupação, responsabilidade e envolvimento afetivo com o outro. Esta afirmativa aponta para o cuidado, como objeto de trabalho da Enfermagem, pois este precisa ser permeado destas qualificações, porque ao exercer a atividade de cuidado enfermeira, cliente, família e sociedade estabelecem uma relação que resulta em uma atitude de cuidado ${ }^{(9-10)}$.

A Enfermagem é uma profissão do cuidar/cuidado, porém, existem entre suas integrantes questionamentos que suscitam dúvidas com relação a seu objeto de trabalho, porque as enfermeiras reconhecem o cuidado como atividade primária, mas referem não assumir em sua integralidade em decorrência de que na dinâmica de trabalho executam tarefas que não são suas, mas por que assumi-las?

Não é possível clarear o campo de competência da Enfermagem sem esclarecer a diferença que perpassa o cuidar e o tratar, no qual o primeiro mobiliza capacidades de vida, promovendo uma diferença significativa entre os dois verbos, porém o significado do tratar invadiu de modo insidioso, o cuidar revestiu-se dele no que se refere ao cuidado dispensado aos seres humanos ${ }^{(8)}$.

O campo de competência da Enfermagem só deixará de ser confuso e arbitrário, quando houver clareza do tipo de substituição exercida pelas profissionais, já que o cuidado de Enfermagem sobrepõe-se aos utilizadores. No que concerne ao campo de competência da Enfermagem, está fundamentalmente baseado em todos os cuidados de manutenção da vida, devendo mobilizar as capacidades da vida em relação com as incidências da doença ${ }^{(8)}$.

No cuidar (to care ${ }^{d}$ ), percebemos que tem perdido espaço entre as enfermeiras para o curar

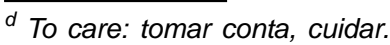


(to cure $^{\mathrm{e}}$ ), porque estas profissionais têm assumido em maior escala os cuidados de reparação e delegado os de manutenção da vida a outras categorias da Enfermagem sob a forma de tarefas, não estabelecendo uma relação entre si, o que contribui para ao empobrecimento do cuidado e a fomentação de dúvidas, quanto ao objeto de trabalho da profissão.

Portanto, faz-se necessário discernir sobre a natureza dos cuidados, baseada no vocabulário inglês dois tipos de cuidados com natureza diferente são apontados, quais sejam: os cuidados quotidianos e habituais ou cuidados de sustento e manutenção da vida (care), podendo ser de natureza alimentar, afetiva, psicossocial e que são fundamentados em toda a espécie de hábitos de vida, costumes e crenças e os cuidados de reparação (cure) que asseguram a continuidade da VIDA diante de obstáculos, tendo como fim limitar a doença, lutar contra ela e atacar as suas causas ${ }^{(8)}$.

Nesta perspectiva, o cuidado de Enfermagem faz parte de um conjunto de atividades do cuidado (care) que é historicamente construído, porém, ao sofrer as influências do modelo biomédico esta profissão tem relegado a segundo plano os cuidados que têm sentido de assegurar a continuidade da vida do ser humano e sua razão de existir ${ }^{(8)}$.

Observamos que seguir este modelo tem implicações importantes para a profissão, pois causa uma ambigüidade entre as profissionais a ponto de terem dificuldades na definição de seu objeto de trabalho, conforme mostram os DSCs.

...Quanto mais trabalho como enfermeira mais acho complicado essa questão do trabalho de enfermagem, mais hoje vejo que é muita responsabilidade, hoje a

\footnotetext{
e To cure: curar, tratar.
}

gente queira ou não queira a gente não responde só pelo nosso serviço, (...) a gente é sobrecarregado, então a gente acaba não fazendo,não tem tempo de um contato maior com o paciente...(DSCsenfermeiras).

...Complicado, acho que o cuidar não é prerrogativa da enfermagem, a gente fecha muito na história do cuidar e talvez a gente se volte muito pro cuidar material, né o cuidar da dor física, ...(DSCs-docentes).

...Acho assim que o trabalho da Enfermagem ainda não tá definido, não consigo assim dizer é isso o trabalho da Enfermagem é esse aqui... durante todo curso a gente aprende é esse cuidado manual, esse cuidado direto do cliente... acho que o trabalho da Enfermagem ainda não alcançou uma autonomia, respeito né, acho que o próprio enfermeiro ele ainda não se definiu enquanto profissional (...) (DSCs-alunas).

Uma das maneiras para superar a incerteza do trabalho da Enfermagem é identificar os elementos que participam na construção do processo de cuidados, que são definidos, como sendo o conhecimento, considerando as fontes utilizadas e seu modo de organização e de utilização, tendo como primeira fonte a pessoa ou o grupo implicado ${ }^{(8)}$.

Ainda são consideradas como componentes do processo de cuidados as tecnologias, por meio das quais o corpo constitui-se no primeiro instrumento de cuidado, levandose em conta as tecnologias ligadas aos cuidados quotidianos e habituais de manutenção da vida, tais como: banhar-se, alimentar-se dentre outros; as de reparação que invadiram progressivamente o campo dos cuidados de Enfermagem, nas quais as profissionais passam a ser executoras dos cuidados prescritos pelos médicos, o que tem contribu- ído para um direcionamento da aprendizagem, essencialmente, às técnicas, por fỉm, as de informação. Outros elementos são as crenças e valores dos envolvidos no processo de cuidado.

Esta assertiva ganha força e necessidade de discussão, baseada nos DSCs construídos pelos sujeitos deste estudo que vivenciam o cotidiano da profissão e, em sua maioria, foi construído por mulheres.

..Você percebe que a enfermagem ainda está numa posição inferior, (...) porque o processo do cuidar também nãoé valorizado, ... (DSCsalunas).

Os encantos e desencantos da ciência no mundo globalizado pela comunicação tecnológica apontam a necessidade de rupturas epistemológicas para a construção de uma nova configuração do saber que garanta a evidencia da exclusão e da opressão ${ }^{(1)}$.

Esta afirmação vem ao encontro do que é vivenciado no seio da Enfermagem, na qual a condição de oprimida nos âmbitos de trabalho, configurada pela desvalorização do cuidar só poderá ser construída com rupturas no saber e fazer reconstruindo os saberes que valorizem as produções nascidas não só da objetividade, mas também da subjetividade criando, assim, uma dinâmica de complementaridade.

A dicotomia tem sido a prerrogativa que atravessa as práticas de saúde no mundo moderno, nas quais o objetivo atua como soberano nas atitudes humanas e a Enfermagem mesmo historicamente estando vinculada à atividade de cuidar/cuidado sofre essa influência, o que tem construído lacunas em seu saber e fazer. Para superar o estabelecido, é preciso uma (re) construção, na qual as diversas expressões de cuidado sejam consideradas e valoradas independente do tipo de tecnologia utilizada. 
Por outro lado, os discursos de docentes, alunas e enfermeiras egressas também revelaram, como sendo objeto de trabalho da Enfermagem o cuidar/cuidado, constituindo a tarefa primordial da profissão e que este é relacional, o que vem ao encontro da assertiva de que a noção de cuidar (care), envolve a dimensão da afetividade, implicando certos valores, qualidades e sentimentos, tais como:

... a atenção ao outro; a sensação de inquietação pelo outro; o sentimento de estar concernido, interessado, empenhado; relacionarse através do caminho da ternura, de maternagem, estas são todas qualidades transformadas em qualificações que não implicam, ao serem práticas, na ausência de procedimentos médicos, científicos e técnicos... ${ }^{(11)}$.

Esta afirmativa sobre a noção de cuidar em enfermagem corrobora com os DSCs apresentados a seguir que defendem o cuidado como objeto de trabalho da profissão e que este é construído baseado em uma relação empática entre os envolvidos.

...É o cuidar, o cuidar do paciente do serviço que a gente trabalha, é o trabalho do cuidar, onde você aprende a cuidar do outro cuidando de você mesmo, se você não tem amor, você não pode dá carinho, se você não tem e não sabe perceber o que é isso, então o trabalho da enfermagem é o cuidar do ser humano independente de sua religião, sexo, idade fazendo com que aquele outro possa ter em você confiança, estabelecer uma relação e a partir dessa relação que você estabelece, você possa prestar um cuidado, seja de forma técnica, cientifica, ... o cuidar (...) é um toque, é o ouvir, ... .A gente tem que ter muita sensibilidade pra poder definir não só o que é o objeto, mas pra você en- tender como é que se processa o trabalho da Enfermagem, ... (DSCS - enfermeiras).

...O objeto de trabalho da Enfermagem é o cuidar, pois ela cuida de forma orientada, planejada, sistemática, visando promover o bem-estar e a melhoria da saúde dos indivíduos sob seus cuidados; ele é o foco central do trabalho da enfermagem, é um processo vivo que precisa de ação e resolutividade... (DSCs docentes).

... o cuidar mesmo é assim uma relação mais estreita... é uma coisa mais próxima... É o cuidar do paciente, mais seu todo;... é cuidar de seres humanos; é essencial pra recuperação do paciente, ... esse cuidado, ele tem assim tamanha importância, porque ele vai proporcionar ao paciente que ele tenha as necessidades básicas satisfeitas... o objeto de trabalho da Enfermagem requer atenção de todos os níveis, que ele possui todas as dimensões físico, psíquico, espiritual que realmente é necessário a gente vê isso, apesar de haver uma grande demanda pra poucos recursos (...) (DSCs - alunas).

...o processo de cuidados de enfermagem procede de um encontro entre dois (ou mais) seres vivos em que cada um detém elementos do processo de cuidados... ${ }^{(8)}$,

portanto situado numa encruzilhada de um sistema de trocas que emergem de diversas fontes, determinando a natureza dos cuidados a fornecer e os meios de os desencadear.

No que se refere ao cuidado como momento de encontro e troca,

[...] não podemos negar que sob o império da razão, inúmeras limitações foram impostas à compreensão - ação do cuidado[... ${ }^{(12)}$.
Os achados apontaram para o cuidar/cuidado como sendo uma práxis relacional, o que vem ao encontro da noção de cuidado, como trabalho singular que estabelece vínculos relacionais entre afetividade $\mathrm{e}$ ciência ${ }^{(11)}$. Julgamos que o estabelecimento de uma relação dessa natureza contribuirá para a reconstrução do saber e fazer da Enfermagem como profissão do cuidado.

As enfermeiras estão permanentemente ao lado de quem vivencia o processo de saúde e doença, tendo acesso a seus signos corporais mais privados e íntimos do corpo, como a ansiedade, o medo, a angústia, a esperança, o sofrimento, a vergonha. Estes são apreendidos, mediante diferentes formas de expressão da linguagem, e, não pela competência técnica ${ }^{(1)}$.

[...] é a possibilidade da prática da Enfermagem incorporar e valorizar como instrumentos de trabalho estas dimensões que exigem competência e atenção próprias e pessoais[..] ${ }^{(11)}$.

A singularidade do cuidar/cuidado emerge da aliança entre a técnica e a relação estabelecida entre as pessoas. Diante da evidência de que a prática social da Enfermagem, é relacional, as enfermeiras precisam buscar desvelar no cotidiano as possíveis dimensões do cuidar/cuidado, dentro de uma perspectiva de aproximação antropobiológica ${ }^{\dagger}$, na qual prestadoras e utilizadores do cuidar/ cuidado contribuam no processo desta atividade ${ }^{(8)}$.

\section{CONSIDERAÇÕES FINAIS}

Diante das narrativas dos sujeitos estudados, nesta pesquisa, observamos dúvidas e indefinições em relação ao objeto de trabalho da Enfermagem, porém também ficou cla-

\footnotetext{
${ }^{f}$ Diz respeito aos seres humanos inseridos no seu meio, composto por todas as espécies de laços simbólicos ${ }^{(8)}$.
} 
ro que o cuidar/cuidado é o objeto de trabalho da profissão sendo uma práxis relacional.

O cuidar/cuidado como objeto de trabalho da Enfermagem é ensinado e aprendido de modo não sistemático, havendo uma valorização significativa dos procedimentos técnicos e conteúdos, o que tem comprometido a questão relacional do cuidado. Isso tem contribuído para o desenvolvimento entre as profissionais de um saber que acabam por valorizar os cuidados de recuperação da saúde (cure).

Consideramos importante que as integrantes do Curso de Graduação em Enfermagem, em especial, a Área de Conhecimento estudada busquem clarificar as dimensões do cuidar/cuidado no sentido de trabalhar os conteúdos que privilegiam as ações do curar e do cuidar de modo equivalente pela complementaridade.

Assim, poderão contribuir com posturas críticas para a construção de um saber e fazer da Enfermagem que sejam valorizados intra e inter categorias, articulados à sociedade. Precisamos investir em diversas estratégias de ensinar e aprender o cuidado, porém, com pontos de convergências que caminhem para a integração.

Amorim RC, Oliveira EM. [The teaching and practices of caring in the nursing.] Acta Paul Enferm 2005; 18(1):25-30.

ABSTRACT: This research has been motivated by the author's own experiences and concens she had during her professional schooling and practice. The aim of this study is to analyse the educational forming process of the nurse. When it comes to the teaching of caring/cared in the nursing course. The emphasis is on the dynamic procedures of the nurse according to the faculty of the Adult Health Field, students and ex-students of the course. Based on previous Knowledge, through the empirical material, the meanings of the teaching and learning of caring/cared have been described and analysed in the search of a reflexion about the educational process of those professionals. The qualitative approach and the study case method have been used and data have been collective from semi-structured interviews. To analyses the material, the strategy of the collective subject discourse has been applied. The analyses of those discourses made it possible to create themes, among which, the one focused on this sudy: caring/cared taken as the scientific object in the nursing practice and its construction for the social practice.

Descriptors: Teaching; Education, nursing; Nursing care
5. Conselho Nacional de Saúde. Resolução n. 196, de 10 de outubro de 1996. Diretrizes e normas regulamentadoras de pesquisas envolvendo seres humanos. Bioética 1996; 5(2):13-41.

6. Richardson RJ, Peres JAS, Wanderley JCV, Correia LM, Peres MHM. Pesquisa social: métodos e técnicas. $3 \mathrm{a}$ ed. São Paulo: Atlas; 1999.

7. Lefèvre F, Lefèvre AMC, Teixeira JJV. O discurso do sujeito coletivo: uma nova abordagem metodológica em pesquisa qualitativa. Caxias do Sul: EDUCS; 2000.

8. Colliére M F. De promover a vida: da prática das mulheres de virtude aos cuidados de enfermagem. Trad. Maria Leonor Braga Abecasis. Lisboa: LIDEL; 1999.

9. Boff L. Saber cuidar: ética do humano - compaixão pela terra. Petrópolis: Vozes; 1999.

10. Waldow V R. Cuidado humano: o resgate necessário. 2a ed. Porto Alegre: Sagra Luzzato; 1999.

11. Bandeira L, Oliveira EM. Representações de gênero e moralidade na prática profissional da enfermagem. Rev Bras Enferm 1998; 51(4):677-96.

12. Silva AL. Cuidado como momento de encontro e troca. In: Anais do $50^{\circ} \mathrm{Con}-$ gresso Brasileiro de Enfermagem; set. 20-25. Salvador (BA). Salvador: ABEn - Seção- BA; 1998. p.74-9.
Amorim RC, Oliveira EM. [La enseñanza y las praticas de cuidado: el caso de un curso de pregrado en enfermeria.] Acta Paul Enferm 2005; 18(1):25-30.

RESUMEN: Vivencias e inquietaciones construídas durante la formación y actuacion profesionales de la autora motivarán esta investigación, que tiene como objeto el proceso de enseñanza del cuidar/cuidado en um curso de Enfermería que tuvo como objetivo analizar el proceso de formación de la enfermera o buscando conocer su dinâmica através de los óptica de la profesores del área de la salud de los adultos, estudiantes y ex estudiantes del curso. Baseado em el conocimento anterior atraves de material empírico, los significados de enseñar asi como aprender acerca de lo cuidar/del cuidado fueran descriptos y analisados, promocionando uma reflexion acerca de la formación de estas profissionales. El abordaje metodológico fue calitativa com el método de estudios de caso. La selección de material que realizado por la técnica de encuestas medio-estructurado. Para el análisis del material, que trabajado la estrategia metodologica del discurso del sujeto colectivo. Los análisis de los discursos hicieran posible la creaccian de temáticas, abordada en este artículo, lo que trata de lo cuidar/del cuidado como objeto de trabajo del enfermaje y su construcción para uma práctica social.

Descriptores: Enseñanza; Educación en enfermería; Atención de enfermería. 